УДК 622.822:622.271

\title{
ПРОМЕРЗАНИЕ ГРУНТОВ ОСНОВАНИЙ ЖЕЛЕЗНЫХ ДОРОГ КАЗАХСТАНА
}

\author{
Доктора техн. наук А.Д. Омаров, Т.С. Саржанов, Г.С. Мусаева
}

ПРОМЕРЗАННЯ ГРУНТІВ ОСНОВ ЗАЛІЗНИЧНИХ ШЛЯХІВ КАЗАХСТАНУ

\author{
Д-ри техн. наук А.Д. Омаров, Т.С. Саржанов, Г.С. Мусаєва
}

\section{FREEZING GROUNDWATER BASED KAZAKHSTAN RAILWAYS}

\author{
Doctors of techn. sciences A.D. Omarov, T.S. Sarzhanov, G.S. Musaeva
}

У запропонованій статті на основі аналізу стану трунтів та гірських порід в різний час року встановлена глибина промерзання $i$ тривалість мерзлого періоду, щяо дозволило виконати районування території Казахстану за иією важливою ознакою, яка впливає на працездатність земляного полотна залізниць.

Ключові слова: залізниця, земляне полотно, трунт, промерзання, підзона, районування.

В предлагаемой статье на основе анализа состояния грунтов и горных пород в различное время года установлена глубина промерзания и продолжительность мерзлого периода, что позволило выполнить районирование территории Казахстана по этому важному признаку, влияющему на работоспособность земляного полотна железных дорог.

Ключевые слова: железная дорога, земляное полотно, грунт, промерзание, подзона, районирование.

In this article on the basis of analysis the condition of soil and rock in the different times of year is planted depth of freeze and duration of freezing period, that allowed to carry out dividing the territory of Kazakhstan on this important sign, influencing for the capacity for work of permanent railway track.

Study of climatic conditions allowed to establish water-heat mode subgrade, choose the rational design, to justify the estimated subgrade soil conditions, as well as solve other engineering problems related to design and construction, and operation of railways.

Keywords: permanent way, soil, freezing, dividing zone.

Введение. Изучение и оценка физикомеханических свойств грунтов и горных пород необходимы для проектирования, строительства и эксплуатации пути и являются одними из наиболее сложных и наименее изученных проблем в области физических процессов, происходящих в горном массиве и основании железнодорожного пути. На практике изучение свойств грунтов и горных пород ограничивается лабораторными исследованиями, без учета динамических воздействий подвижного состава на путь и длительности эксплуатации железных дорог.

Постановка задачи. Такой подход не удовлетворяет запросам проектировщиков, строителей и эксплуатационников железных дорог, поэтому необходимо изучить и оценить грунтовое основание магистральных и карьерных железных дорог, что позволит определить вероятность появления грунтов различного типа, лежащих в основании железных дорог, а также пределы изменения физикомеханических свойств наиболее распространенных грунтов. 
Изложение материала. В 1974 году А.А. Малышев и другие ученые [1] публикуют схему районирования. Относительная однородность выделенных районов установлена по четырем факторам: виду грунта сезоннооттаивающего слоя; его влажности; характеру распределения вечномерзлых грунтов и их температур; мощности деятельного слоя.

Занимаясь вопросами районирования, B.M. Сиденко предложил перейти от дорожно-климатического к дорожному районированию, представляя его как метод объединения однородных территорий по каким-либо признакам, которые оказывают существенное влияние на проектирование, строительство и эксплуатацию дорог [2]. Он ставит вопрос о необходимости разработки зональных технических условий, которые должны отражать особенности природных условий и специфику проектирования, строительства и эксплуатации дорог в каждой зоне, дополнив Строительные нормы СН 449-72.

Из зарубежных работ, посвященных данной теме, можно выделить работу «Зависимость проектирования дорог от местных физико-географических условий», где обобщены сведения о местных дорожно-строительных материалах, несущей способности грунтов и их изменения под влиянием увлажнения. По комплексу этих условий территория США разделена на 97 физико-географических районов.

В последнее время наметилась тенденция к созданию различного рода математических моделей географической среды. В частности, Smith W.L. предлагает вероятностную модель оценки окружающей среды, землеиспользования, плотности населения и других факторов [3]. Метод трассирования с помощью «стоимостных линий и зон» предложен Othanassoulis G.C. и Calogero V.F. [4]. Американские специалисты Kuhn J.A. и Goggin J. предложили систему анализа природных условий и хозяйственной деятельности человека с помощью специальных карт [5].
По данным В.М. Сиденко [6-8], в рассматриваемых подзонах распространены сероземы, пески и почвы горных районов. Сероземы макропористы, отличаются высоким содержанием в грунтах пылеватых частиц, преобладанием легких пылеватых суглинков и тяжелых пылеватых супесей. Они относятся к пучинистым и сильнопучинистым грунтам, легко размокают при увлажнении, в сухом состоянии плохо сопротивляются внешним воздействиям и на грунтовых поверхностях под действием автомобилей быстро истираются и превращаются в несвязную массу.

Важной

характеристикой, определяющей водно-тепловой режим грунтов полотна, являются осадки, величина годовой суммы которых на территории Казахстана колеблется от 75 мм в юго-западной до 300 мм в юго-восточной и северо-восточной частях. Основное количество осадков выпадает в зимневесенний период [9]. Следовательно, даже небольшое годовое количество осадков, при их неравномерном выпадении во времени, может существенно повлиять на влагонакопление в полотне и, как следствие, на образование деформаций на основной площадке, при наличии или отсутствии балластного слоя, а также на устойчивость откосов земляного полотна.

Изучение природно-климатических условий позволяет установить воднотепловой режим земляного полотна, выбрать рациональную конструкцию, обосновать расчетное состояние грунта земляного полотна, а также решить другие инженерные задачи, связанные с проектированием и строительством, эксплуатацией железных дорог.

На работу земляного полотна и балластной призмы большую роль оказывает продолжительность мерзлого состояния грунтов, так как в зимнее время повышается жесткость пути, повышается сопротивляемость грунтов сдвигу.

При действии поездной нагрузки и при повышенной влажности в отдельных точках грунтового массива земляного 
полотна эффективные напряжения могут превзойти внутренние связи между частицами грунта, при этом могут возникнуть скольжения (сдвиги) одних частиц или их агрегатов по другим и нарушатся сплошность грунта в некоторой области, т.е. прочность грунта будет исчерпана. При замерзании грунтового массива внутренние связи между частицами повышаются и грунт становится прочным.

В песчаных грунтах внутренним сопротивлением, препятствующим сдвигу частиц, будет трение, возникающее в точках контакта частиц. В идеально связных грунтах (вязкие дисперсные глины) силами внутреннего сопротивления сдвигу будут структурные связи и вязкость водно-коллоидных частиц, т.е. силы сцепления. В глинистых грунтах (супеси, суглинки и глины) сопротивление сдвигу обусловлено трением и сцеплением.

Определение показателей сопротивления грунтов сдвигу имеет важное значение для строительной практики, т.к. обусловливает точность инженерных расчетов грунтов: определение предельной нагрузки на грунт, устойчивости массивов грунта, давлений на подпорные стенки и др.

Профессором А.Н. Зелениным установлена связь меду прочностью грунта и температурой его промерзания [10]:

$$
C=A \cdot t^{0,5},
$$

a также закономерность изменения температуры мерзлого фунта от глубины залегания

$$
t=A \cdot h^{0,5}
$$

В формулах (1) и (2): $A$ - коэффициент, определяемый экспериментальным путем; $t$ - температура фунта; $h$ - глубина залегания, м.

Используя фактические показатели прочности грунта $C$, определим глубину промерзания $h$ для участков железных дорог Казахстана [11,12]. В табл. 1 приведена глубина промерзания грунтов и продолжительность мерзлого состояния грунтов по некоторым участкам железных дорог Казахстана.

Таблица 1

Глубина промерзания грунтов и продолжительность мерзлого состояния грунтов по некоторым участкам железных дорог Казахстана

\begin{tabular}{|l|c|c|}
\hline \multicolumn{1}{|c|}{ Участки железных дорог } & $\begin{array}{c}\text { Продолжительность мерзлого } \\
\text { состояния грунтов, мес. }\end{array}$ & $\begin{array}{c}\text { Среднемаксимальная глубина } \\
\text { промерзания, м }\end{array}$ \\
\hline Отар - Сары-Озек & 4,7 & 0.44 \\
\hline Сары-Озек - Актогай & 4,4 & 0,35 \\
\hline Отар - Шу & 4,0 & 0,29 \\
\hline Саксаульская - Сатимсак & 4,6 & 0,45 \\
\hline Опорный - Узень & 4,3 & 1,0 \\
\hline Сагиз - Атырау & 3,0 & 0,8 \\
\hline Уральск - Чингирлау & 4,5 & 1,2 \\
\hline Кандагач - Саксаульская & 5,9 & 1,6 \\
\hline Ерментау - Павлодар & 5,7 & 2,3 \\
\hline Койбагар - Сергеевка & 4,9 & 1,6 \\
\hline Макинск - Новоишимская & 5.9 & 2.4 \\
\hline Астана - Осакаровка & 5,8 & 2,3 \\
\hline Новоишимская - Кустанай & 5,8 & 2,3 \\
\hline Жарык - Жезказган & 4,6 & 1,2 \\
\hline Осакаровка - Южный & 4,6 & 1,2 \\
\hline Шемонаиха - Зыряновск & 5,4 & 1,0 \\
\hline Актогай - Семей & 5,2 & 1,4 \\
\hline
\end{tabular}




\begin{tabular}{|c|c|}
\hline 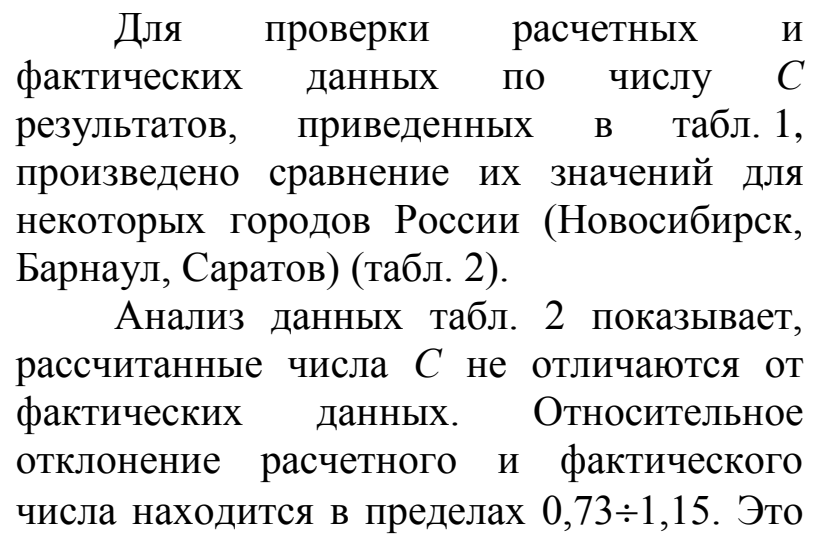 & $\begin{array}{l}\text { показывает, что вышеуказанная методика } \\
\text { определения числа } C \text { вполне приемлема для } \\
\text { инженерных расчетов. } \\
\text { Установленные свойства грунтов } \\
\text { позволили районировать территорию } \\
\text { Казахстана по глубине промерзания и } \\
\text { продолжительности мерзлого состояния } \\
\text { грунтов и горных пород оснований } \\
\text { магистральных и карьерных железных } \\
\text { дорог Казахстана. На рисунке приведена } \\
\text { карта Казахстана с указанием этих районов. }\end{array}$ \\
\hline
\end{tabular}

Таблица 2

Расчетные и фактические данные числа $C$ ударника ДорНИИ от глубины мерзлого слоя грунта

\begin{tabular}{|c|c|c|c|c|c|c|c|c|c|}
\hline \multirow{3}{*}{$\begin{array}{c}\text { Глубина } \\
\text { от } \\
\text { поверх- } \\
\text { ности } \\
\text { грунта, } \\
\text { см }\end{array}$} & \multicolumn{9}{|c|}{ Фактические и расчетные значения числа $C$ и их относительные отклонения } \\
\hline & \multicolumn{3}{|c|}{ Саратов } & \multicolumn{3}{|c|}{ Барнаул } & \multicolumn{3}{|c|}{ Новосибирск } \\
\hline & $\begin{array}{l}\text { Факти- } \\
\text { ческие }\end{array}$ & $\begin{array}{c}\text { Расчет- } \\
\text { ные }\end{array}$ & $\begin{array}{l}\text { Откло- } \\
\text { нение }\end{array}$ & $\begin{array}{l}\text { Факти- } \\
\text { ческие }\end{array}$ & $\begin{array}{c}\text { Расчет- } \\
\text { ные }\end{array}$ & $\begin{array}{l}\text { Откло- } \\
\text { нение }\end{array}$ & $\begin{array}{l}\text { Факти- } \\
\text { ческие }\end{array}$ & $\begin{array}{c}\text { Расчет- } \\
\text { ные }\end{array}$ & $\begin{array}{l}\text { Откло- } \\
\text { нение }\end{array}$ \\
\hline 160 & - & - & - & 60 & 65 & 0,93 & 100 & 105 & 0,95 \\
\hline 120 & - & - & - & 135 & 140 & 0,96 & 150 & 165 & 0,91 \\
\hline 100 & 25 & 30 & 0,73 & - & - & - & 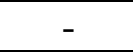 & - & - \\
\hline 80 & 75 & 65 & 1,15 & 210 & 215 & 0,98 & 200 & 220 & 0,91 \\
\hline 40 & 135 & 150 & 0,9 & 285 & 290 & 0,98 & 265 & 280 & 0,95 \\
\hline 0 & 220 & 220 & 1 & 360 & 360 & 1 & 340 & 340 & 1 \\
\hline
\end{tabular}

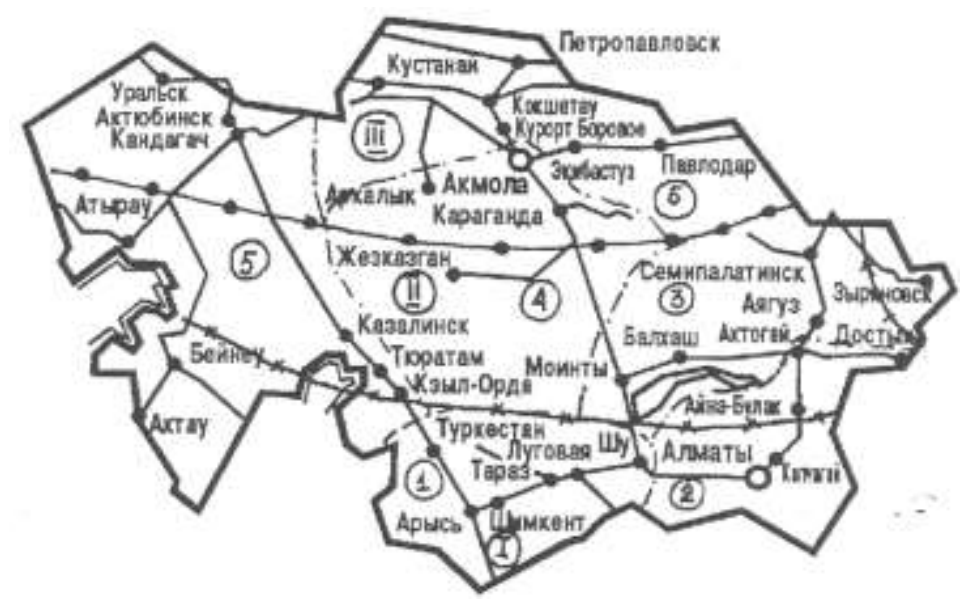

Рис. Условные зоны железных дорог Казахстана:

1 - территория по глубине промерзания грунта до 1 м; II - территория по глубине промерзания грунта от 1 до 2 м; III - территория по глубине промерзания грунта свыше 2 м; 1,2,3,4,5 - зоны территории железных дорог Казахстана 
Вывод. На основе анализа состояния грунтов и горных пород в различное время года установлена глубина промерзания и продолжительность мерзлого периода, что позволило выполнить районирование территории Казахстана по этому важному признаку, влияющему на работоспособность земляного полотна железных дорог.

\section{Список использованных источников}

1. Малышев, А.А. Земляное полотно автомобильных дорог в северных условиях [Текст] / А.А. Малышев [и др.]. - М.: Транспорт, 1974. - 279 с.

2. Сиденко, В.М. Автомобильные дороги (Совершенствование методов проектирования и строительства) [Текст] / В.М. Сиденко [и др.]. - К.: Будівильник, 1973. - 76 с.

3. Smith, W.L. Rational location of a highway corridor: a probabilistic approach [Text] / W. L. Smith // Highway Res. Rec. - 1971. - № 348. - P. 42-60.

4. Athanassoulis, G.G. Computer technique for route planning [Text] / G.G. Athanassoulis, V.A. Calogero // Highway Eng. - 1973. - №4, v.1. - P. 20.

5. Kuhn, J.A. Environmental mapping: an ecological methodalogy for highway impact analysis [Text] / J.A. Kuhn, J.L. Gaggin // Abragment. Highway Res. Rec. - 1973 - № 467. - P. 26-33.

6. Сиденко, В.М. Проектирование, строительство и организация возведения земляного полотна в засушливых районах [Текст]: учеб. пособие для студентов автодорожных спец. вузов / В.М. Сиденко, Н. Ильясов. - Т.: Укитувчи, 1983. - 288 с.

7. Сиденко, В.М. Расчет и регулирование водно-теплового режима дорожных одежд и земляного полотна [Текст] / В.М. Сиденко. - М.: Автотрансиздат, 1962. - 156 с.

8. Водно-тепловой режим земляного полотна и дорожных одежд [Текст] / Н.А. Пузаков, В.М. Сиденко [и др.]; под ред. проф. И.А. Золотаря. - М.: Транспорт, 1971. - 416 с.

9. Фазилов, Т.Н. Закрепление подвижных песков вяжущими веществами [Текст] / Т.Н. Фазилов. - Ташкент: Фан, 1987. - 103 с.

10. Зеленин, А.П., Баловнев В.И., Керов И.П. Машины для землеройных работ [Текст] / А.П. Зеленин, В.И. Баловнев, И.П. Керов. - М.: Машиностроение, 1975. - 422 с.

11. Кабашев, Р.А. Дорожные и строительные машины: абразивный износ рабочих органов землеройных машин [Текст] / Р.А. Кабашев. - Алматы: Ғылым, 1997. - 424 с.

12. Омаров, А.Д. Грунтовый фон оснований железных дорог Казахстана [Текст] / А.Д. Омаров; под ред. д.т.н., проф. Р.А. Кабашева. - Алматы: «Ғылым», 1998. - 110 с.

Омаров Амангельды Джумагалиевич, доктор технических наук, профессор, действительный член Международной академии транспорта, действительный член Международной академии информатизации, Президент Учреждения «Многопрофильный учебно-научно производственный комплекс, Гуманитарный Университет транспорта и права имени Д.А. Кунаева», ректор ГУТиП им. Д.А.Кунаева, (Республика Казахстан, Алматы).

Саржанов Тайжан Садыханович, доктор технических наук, профессор института путей сообщения при ГУТиП им. Д.Кунаева, (Республика Казахстан, Алматы).

Мусаева Гульмира Сериковна, доктор технических наук, профессор Казахской академии транспорта и коммуникаций имени М.Тынышпаева, (Республика Казахстан, Алматы).

Omarov Amangeldi Dzhumagalievich, doct. of techn. sciences, professor, member of the International Academy of Transport, Member of the International Academy of Informatization, president of the institution, "Multidisciplinary educational, research and production complex, University of Humanities and Law of transport DA Kunaeva "Rector GUTiP them. DAKunaev (Almaty, Kazakhstan).

Sarzhanov Tayzhan Sadyhanovich, doct. of techn. sciences, professor at the Institute of Communications GUTiP them. D.Kunaev (Almaty, Kazakhstan).

Musaeva Gulmira Serikovna, doct. of techn. sciences, professor of the Kazakh Academy of Transport and Communication named M. Tynyshpaev (Almaty, Kazakhstan). 